03

\title{
Экспериментальное исследование влияния наночастиц на процессы испарения жидкостей
}

\author{
(C) А.В. Минаков, ${ }^{1,2}$ А.С. Лобасов, ${ }^{1,2}$ М.И. Пряжников, ${ }^{1,2}$ Л.С. Тарасова, ${ }^{3}$ Н.Я. Василенко, ${ }^{1}$ В.Я. Рудяк ${ }^{1}$ \\ ${ }^{1}$ Сибирский фредеральный университет, \\ 660056 Красноярск, Россия \\ ${ }^{2}$ Институт теплофизики СО РАН, \\ 630090 Новосибирск, Россия \\ ${ }^{3}$ Федеральный исследовательский центр „КНЦ СО РАН“, \\ 660036 Красноярск, Россия \\ e-mail:perpetuityrs@mail.ru
}

Поступило в Редакцию 19 февраля 2019 г.

В окончательной редакции 19 февраля 2019 г.

Принято к публикации 15 апреля 2019 г.

Экспериментально изучено испарение наножидкостей на основе дистиллированной воды и наночастиц диоксидов кремния и циркония, оксида алюминия, а также наночастиц алмаза. Средний размер наночастиц $\mathrm{SiO}_{2}$ равен $25 \mathrm{~nm}$, для частиц $\mathrm{ZrO}_{2}-105 \mathrm{~nm}$, для частиц $\mathrm{Al}_{2} \mathrm{O}_{3}-43 \mathrm{~nm}$ и алмаза $-5 \mathrm{~nm}$. Исследование процесса испарения проведено с помощью синхронного термоанализатора STA 449 C Jupiter. Исследована зависимость скорости испарения от объемной концентрации наночастиц. Показано, что с увеличением концентрации наночастиц скорость испарения жидкости монотонно возрастает.

Ключевые слова: наножидкость, испарение, наночастицы, темп испарения, термогравиметрия, термоанализ.

DOI: $10.21883 / J T F .2020 .01 .48657 .61-19$

\section{Введение}

Проблема интенсификации теплообмена и связанные с ней задачи экспериментального и теоретического исследований приобретают в настоящее время значение самостоятельной, быстро развивающейся области учения о теплообмене. Во всех машинах, оборудовании и технологиях возникает потребность интенсивного отведения тепла, для чего используется различного рода теплообменное оборудование. Актуальность этой проблемы определяется стремлением добиться максимальной компактности при минимальной материалоемкости, повышению интенсивности работы теплообменных устройств в сочетании с желанием сократить затраты энергии.

Одним из путей решения проблемы интенсификации процесса теплообмена является использование в теплообменных устройствах в качестве теплоносителей жидкостей с примесью наночастиц различного состава, получивших название „наножидкостей“.

Термин „наножидкость“ был впервые предложен в работе [1] для обозначения двухфазной системы, состоящей из несущей жидкости и наночастиц высокотеплопроводного материала. Типичными несущими жидкостями являются вода, органические жидкости (этиленгликоль, масло), полимерные растворы. Материалом для наночастиц служат металлы, оксиды металлов, углеродные нанотрубки и т.д. Многочисленные исследования показали, что наножидкости обладают рядом особых свойств. Теплопроводность наножидкостей значительно превышает теплопроводность несущей жидкости (от процентов до сотен процентов для нанотрубок) [2,3]. В отличие от крупных дисперсных частиц наночастицы слабо седиментируют и не подвергают эрозии каналы, по которым движутся. В связи с этим наножидкости могут успешно использоваться для охлаждения различных устройств, при создании новых систем транспортировки и производства тепловой энергии, в микроэлектромеханических системах (МЭМС), при создании смазочных материалов, в системах очистки воздуха и воды и др. Это позволяет повысить интенсивность теплоотдачи при охлаждении различных устройств.

Проведенные эксперименты по ламинарной и турбулентной вынужденной конвекции наножидкостей на основе воды и наночастиц различного состава показали, что наножидкости способны повысить значение коэффициента теплоотдачи на 30-40\% [4-6].

Следует ожидать, что добавки наноразмерных частиц могут оказывать влияние на испарение жидкостей. При этом скорость испарения является ключевым параметром, влияющим на эффективность различных технологических процессов. В связи с этим в последнее время было проведено достаточно большое количество исследований в области испарения наножидкостей. Однако анализ литературы показывает, что результаты этих исследований весьма противоречивы.

В работе [7] было исследовано влияние наночастиц алюминия (с размером ориентировочно около $80 \mathrm{~nm}$ ) на динамику испарения и смачивания этанола при различных температурах. Концентрация наночастиц была равна 2 vol.\%. Было показано, что скорость испарения нано- 
жидкости на начальном этапе примерно на 10\% меньше, однако время полного испарения капель существенно выше, чем у базовой жидкости. Было установлено, что на динамику процесса испарения капель определяющее влияние оказывает смачиваемость подложки. При этом было показано, что на начальных этапах испарения краевой угол для наножидкости был выше, чем для базовой жидкости, а к концу процесса испарения наоборот. Этим авторы работы и объясняют то, что полное время испарения капель наножидкости меньше, чем в базовой жидкости.

В работе [8] исследована скорость испарения капель этанола с частицами алюминия $(80 \mathrm{~nm})$ и его оксида $(25 \mathrm{~nm})$ концентрацией $5 \mathrm{wt} . \%$ под действием теплового излучения. Установлено, что скорость испарения наножидкости на 10-15\% выше, чем скорость испарения чистой жидкости. По мнению авторов, это объясняется большим по сравнению с чистой жидкостью коэффициентом поглощения теплового излучения.

А.Д. Назаров и др [9] экспериментально исследовали испарение подвешенных капель наножидкости с частицами оксида кремния $(10 \mathrm{~nm}, 0.1 \mathrm{wt} . \%)$. Показано, что капли наножидкости испаряются медленнее, чем капли базовой среды. Кроме того, было обнаружено, что динамика испарения капель наножидкости является нелинейной и состоит из двух частей, которые могут быть аппроксимированы прямыми линиями с разными углами наклона. Это, вероятно, связано с тем, что в процессе испарения малых капель происходит изменение концентрации наночастиц, которое меняет свойства наножидкости. В более ранней работе [10] этой же группы авторов показано, что заметное влияние наночастиц на скорость испарения капель начинается тогда, когда концентрация наночастиц превышает 3 wt.\%. Было установлено, что при больших концентрациях наночастиц время испарения капли сокращается на 40\%. При этом зависимость от концентрации наночастиц является нелинейной.

В работах В.И. Терехова $[11,12]$ изучено испарение капель воды с углеродными нанотрубками с концентрацией 0.1 wt.\%. Показано, что изменение диаметра капель хорошо обобщается законом „3/2“, а скорость испарения наножидкости практически не отличается от скорости испарения воды.

Помимо скорости испарения во многих работах также исследовалось влияние наночастиц на теплоту испарения. В работе [13] с помощью эксперимента и молекулярно- динамического моделирования было исследовано влияние добавки наночастиц на теплоту испарения. И расчеты, и измерения показали, что небольшое количество наночастиц может значительно изменить теплоту испарения базовой жидкости. Так, добавка 3 wt.\% наночастиц Ag приводит к уменьшению теплоты испарения на $25 \%$, а добавка такого же количества наночастиц Al увеличивает теплоту испарения на $3 \%$. С помощью молекулярной динамики было дано объяснение такого поведения. Сила связи между частицами алюминия и воды оказалась много больше, чем между частицами воды и серебра.

При изучении наножидкостей с частицами $\mathrm{Al}_{2} \mathrm{O}_{3}$ на основе воды было показано [14], что добавка 2 vol.\% наночастиц повышает теплоту испарения примерно на 20\%. В работе [15] было обнаружено, что при добавлении $0.1 \mathrm{vol} \%$ 30-nm графита к деионизированной воде приводит к увеличению теплоты испарения на $36 \%$, а добавка 0.1 vol.\% серебра уменьшает эту величину на $30 \%$. Авторы связывают это поведение со способностью наночастиц разрушать и преобразовывать водородные связи вокруг наночастиц. Графит усиливает водородные связи, серебро ослабляет.

В [16] экспериментально определены характеристики испарения топлив на основе стабильной суспензии углеродных наноструктур при поглощении излучения в ультрафиолетовой и видимой области спектра. В результате было показано, что скорости испарения наножидкостей на основе этанола, содержащие многослойные углеродные нанотрубки и углеродные наночастицы, выше, чем скорость испарения чистого этанола. В результате исследований пожаротушений [17] установлено, что максимальное снижение температуры очага возгорания обеспечивается за счет интенсификации процесса испарения тушащей жидкости, а существенной интенсификации испарения капель воды можно достичь за счет добавления углеродистых частиц размером 50-500 $\mu \mathrm{m}$. При этом времена прогрева и полного испарения капель снижались в 2-3 раза.

C.Y. Тso и C. Chao [18] в отличие от большинства работ исследовали испарение наножидкостей не на каплях, а с большой поверхности $(18.8 \times 12.8 \mathrm{~cm})$ и для большого объема $(600 \mathrm{ml})$. Были рассмотрены наножидкости с частицами $\mathrm{Al}_{2} \mathrm{O}_{3}$ (с размерами 13,20 и $80 \mathrm{~nm})$ и $\mathrm{TiO}_{2}(21 \mathrm{~nm})$ при различных объемных концентрациях (до 2 vol.\%). Результаты показывают, что большинство наножидкостей имеют более низкую по сравнению с базовой жидкостью скорость испарения, особенно с увеличением концентрации наночастиц, но несколько наножидкостей при низких объемных концентрациях показывают большие значения, чем у воды. В работе сделан вывод о том, что скорость испарения наножидкостей, а также их давление насыщенного пара может увеличиваться или уменьшаться в зависимости от их объемной концентрации и типа.

Косвенно процесс испарения наножидкости сейчас интенсивно исследуется в солнечных опреснителях, в которых наножидкость выступает в качестве теплоносителя. В опреснителях добавление наножидкости может повысить эффективность его работы по данным разных исследователей в среднем до 50\% [19-21]. Так, например, в работе [21] показано, что производительность опреснителя на солнечной энергии, с наножидкостью на основе частиц оксида меди в качестве теплоносителя, была почти на $285 \%$ выше, чем у обычной солнечного опреснителя, в то время как в случае использования наножидкости на основе частиц оксида алюминия повыше- 

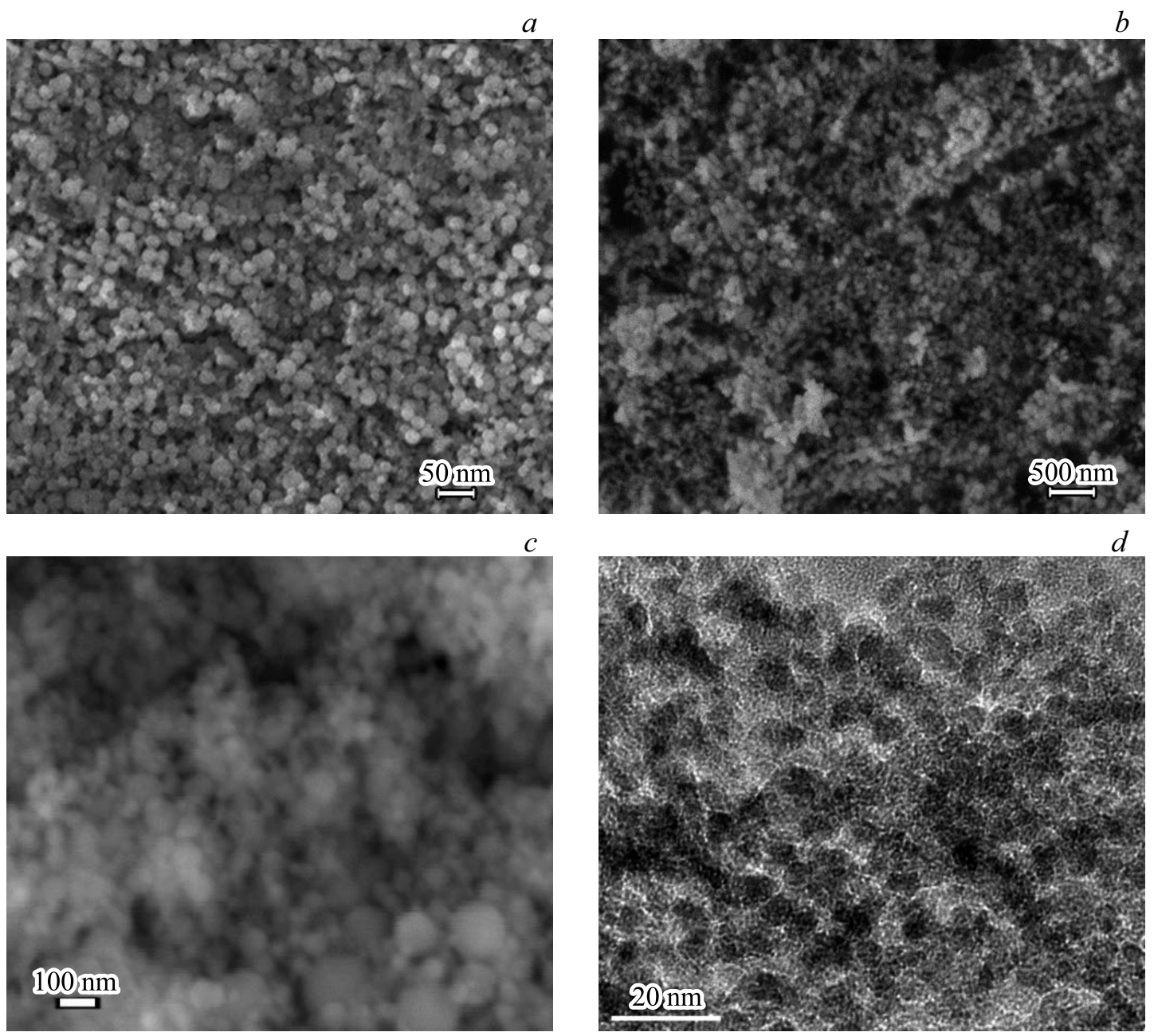

Рис. 1. ПЭМ изображения наночастиц: $a-\mathrm{SiO}_{2} ; b-\mathrm{ZrO}_{2} ; c-\mathrm{Al}_{2} \mathrm{O}_{3} ; d-$ алмаз.

ние производительности составило около 255\%. Однако этот эффект нельзя связывать только с интенсификацией процесса испарения. В большей степени он, вероятно, вызван более высоким значением коэффициента поглощения излучения у наножидкости по сравнению с чистой водой.

Таким образом, несмотря на то, что испарение наножидкостей в последнее время довольно много изучается, как видно из приведенного выше обзора, результаты исследований весьма противоречивы. Есть работы, в которых показано, что добавка наночастиц увеличивает скорость испарения, и есть работы, в которых показано либо отсутствие эффекта при добавлении наночастиц, либо снижение скорости испарения. При этом, несмотря на очень большое количество работ по испарению наножидкости, систематических экспериментальных данных по данной тематике в настоящий момент недостаточно, чтобы ответить на существующие вопросы и устранить противоречия. В связи с этим необходимы дальнейшие экспериментальные исследования. В настоящей работе проведено исследование влияние концентрации и материала наночастиц на скорость испарения наножидко- стей с помощью прецизионного термогравиметрического прибора.

\section{Описание экспериментальной установки и методики проведения исследований}

Исследования скорости испарения были проведены для наножидкостей на основе дистиллированной воды и наночастиц диоксидов кремния $\left(\mathrm{SiO}_{2}\right)$ и циркония $\left(\mathrm{ZrO}_{2}\right)$, оксида алюминия $\left(\mathrm{Al}_{2} \mathrm{O}_{3}\right)$, а также наночастиц алмаза. Средний размер наночастиц $\mathrm{SiO}_{2}$ равен $25 \mathrm{~nm}$, для частиц $\mathrm{ZrO}_{2}-105 \mathrm{~nm}$, для частиц $\mathrm{Al}_{2} \mathrm{O}_{3}-43 \mathrm{~nm}$ и алмаза $-5 \mathrm{~nm}$. Наночастицы оксидов металлов были приобретены у компании „Плазмотерм“, Москва. Порошок алмазов УДА-С (ТУ 84-1124-87) был приобретен у ФНПЦ „Алтай“, г. Бийск. Объемная концентрация наночастиц оксидов металлов варьировала от 0.5 до 6 vol.\%, объемная концентрация наночастиц алмаза варьировала от 0.0625 до 1 vol.\%. Такой выбор диапазонов концентра- 

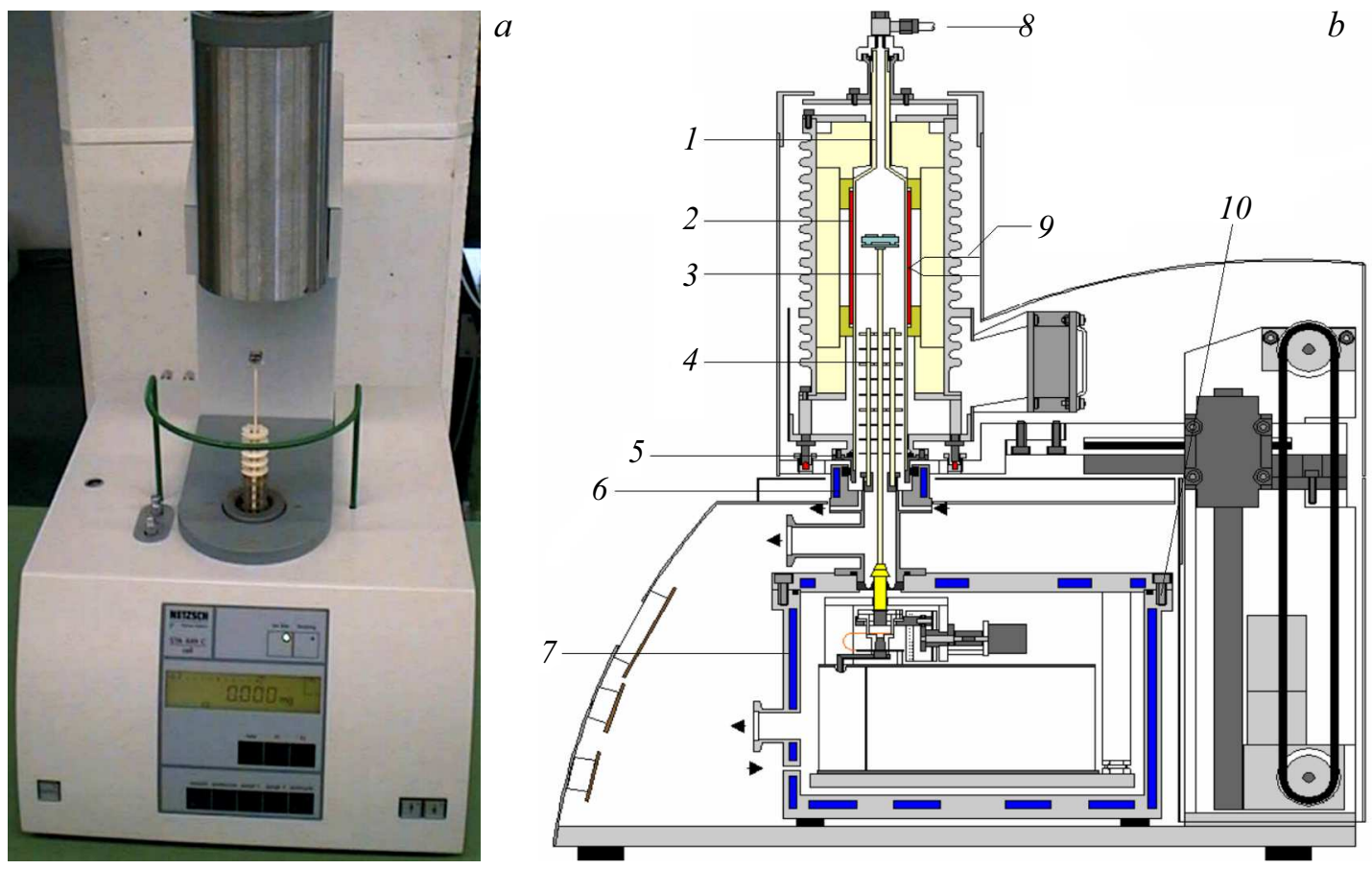

Рис. 2. Синхронный термоанализатор STA 449 C Jupiter $(a)$ и его схема $(b): 1$ - защитная трубка; 2 - нагревательный элемент; 3 - держатель образца; 4 - теплозащитный экран; 5 - вакуумный клапан; 6 - контроль термостатирования; 7 - вакуумплотный корпус; 8 - выход газа; 9 - контролирующая термопара; 10 - система вакуумирования.

ций наночастиц продиктован требованиями к коллоидной устойчивости суспензий.

Для приготовления наножидкости применялся стандартный двухшаговый метод. После добавления в воду необходимого количества нанопорошка емкость с наножидкостью помещалась в ультразвуковую ванну „Сапфир“ для разрушения конгломератов наночастиц. Время ультразвукового диспергирования порошков в воде составляло $30 \mathrm{~min}$. Дальнейшая обработка ультразвуком не приводила к изменению свойств рассматриваемых суспензии. Седиментационная устойчивость высококонцентрированных суспензий оксидов металлов после воздействия ультразвука сохраняется в течение нескольких дней, для суспензий с частицами алмазов в течение суток. Проведенные методические измерения показали, стабильность свойств суспензий в пределах этого времени, что определялось по поведению вязкостей этих суспензий.

Для определения размера наночастиц использовался спектрометр DT-1202. Особенностью акустического спектрометра DT-1202 является то, что в отличие от оптических анализаторов частиц прибор позволяет получать данные о распределении частиц без разбавления суспензии.

Для контроля размера наночастиц также использовались данные электронной микроскопии (рис. 1).

Коэффициент вязкости наножидкостей измерялся с помощью ротационного вискозиметра Brookfield DV2T с адаптером для малой вязкости ULA(0) [22-24]. По- грешность измерения коэффициентов вязкости была не более $2 \%$. Для измерения коэффициента теплопроводности применялся метод нагреваемой проволочки, используемая установка и ее тестирование детально описаны в работах [25-27]. Итоговая относительная погрешность измерения коэффициента теплопроводности составляла около $2 \%$.

Скорость испарения наножидкости была измерена с помощью синхронного термоанализатора STA 449 C Jupiter фирмы NETZSCH (рис. 2,a), сочетающего одновременное измерение изменений массы (термогравиметрия) и тепловых потоков (дифференциальная сканирующая калориметрия). Встроенные электромагнитные микровесы с верхней загрузкой имеют высокоточное разрешение в диапазоне субмикрограмм, а также стабильность измерений.

В процессе синхронного термического анализа исследуется поведение образца в условиях заданной температурной программы. Измеряемыми величинами являются изменение массы, абсолютная температура образца и температурная зависимость разницы между тепловыми потоками образца и эталона. Измерения проводятся синхронно на одном и том же образце в одних и тех же условиях. Схема прибора приведена на рис. $2, b$. Образец наножидкости помещается в корундовый тигель. В работе использовалось несколько тиглей разного объема (20.0 и $85 \mu 1)$. Тигель с жидкостью устанавливается в термостат прибора на специальный держатель, который соединен с высокочувствительными весами. В рабо- 
те использовался платина/платино-родиевый держатель (TG-DSC сенсор типа $S$ ) в сочетании с перфорированными $\mathrm{Al}_{2} \mathrm{O}_{3}$-тиглями. Далее с помощью высокочувствительного нагревателя выставляется необходимый закон изменения температуры в термостате. В процессе эксперимента фиксируется потеря массы образца. Данный прибор позволяет варьировать начальную и конечную температуры образца в процессе нагрева, а также скорость его нагрева и время изотермической выдержки.

В настоящей работе образцы наножидкости подвергались нагреванию от температуры 25 до $50^{\circ} \mathrm{C}$ по температурной программе со скоростью $1 \mathrm{~K} / \min$ в динамической атмосфере воздуха со скоростью потока $30 \mathrm{ml} / \mathrm{min}$ с последующей изотермической выдержкой в течение $30 \mathrm{~min}$. Для всех образцов в процессе эксперимента температура совпадала с достаточно высокой степенью точности. Для каждого образца наножидкостей было проведено по три независимых измерения. Расхождения по скорости испарения между этими измерениями не превышали 4\%.

\section{Результаты исследований и их обсуждение}

Значения коэффициентов вязкости и теплопроводности, рассматриваемых в работе наножидкостей на основе частиц оксидов металлов, представлены на рис. 3. Значения отнесены к значениям коэффициентов вязкости и теплопроводности для чистой воды при температуpe $25^{\circ} \mathrm{C}$.

На рис. 3 также показано сравнение экспериментально измеренных значений коэффициентов вязкости и теплопроводности наножидкостей со значениями, полученными по классическим для дисперсных систем формулам Эйнштейна

$$
\mu / \mu_{f}=1+\frac{5}{2} \varphi
$$

и Максвелла

$$
\frac{\lambda}{\lambda_{f}}=\frac{\lambda_{p}+2 \lambda_{f}+2 \varphi\left(\lambda_{p}-\lambda_{f}\right)}{\lambda_{p}+2 \lambda_{f}-\varphi\left(\lambda_{p}-\lambda_{f}\right)},
$$

где $\varphi$ - объемная концентрация наночастиц, $\mu_{f}, \lambda_{f}-$ коэффициенты вязкости воды и теплопроводности воды, $\lambda_{p}$ - коэффициент теплопроводности частиц.

Как видно, в большинстве случаев измеренное значение коэффициента вязкости и теплопроводности наносуспензий плохо описывается теориями Эйнштейна и Максвелла. Такое поведение свойственно именно наножидкостям в отличие от классических коллоидных растворов [25,27].

Суспензия наночастиц алмазов по своим вязкостным свойствам значительно отличается от рассмотренных суспензий оксидов металлов. Данная суспензия при высоких концентрациях наночастиц является неньютоновской. Ее реология хорошо описывается степенной моделью (power-law): $\mu(\dot{\gamma})=K \dot{\gamma}^{n-1}$, где $\dot{\gamma}-$ скорость
Реологические параметры и относительный коэффициент теплопроводности наножидкости на основе воды при разной объемной концентрации наноалмазов

\begin{tabular}{c|c|c|c|c}
\hline$\varphi, \%$ & $n$ & $K, \mathrm{mPa} \cdot \mathrm{s}^{n}$ & $\lambda_{\exp } / \lambda_{f}$ & $\lambda_{\text {Maxwell }} / \lambda_{f}$ \\
\hline 0.0625 & 0.99 & 0.91 & 1.003 & 1.002 \\
0.125 & 0.96 & 1.76 & 1.005 & 1.004 \\
0.25 & 0.84 & 6.37 & 1.007 & 1.008 \\
0.50 & 0.55 & 24.0 & 1.010 & 1.015 \\
1.00 & 0.42 & 101 & 1.014 & 1.030
\end{tabular}

сдвига, $n$ и $K-$ индекс течения и показатель консистенции реологической модели. В таблице приведены зависимости показателя консистенции и индекса течения от объемной концентрации частиц. С ростом концентрации частиц индекс течения уменьшается, а показатель консистенции растет. Аналогичное реологическое поведение ранее отмечалось и для других наносуспензий [24].

При этом коэффициент теплопроводности наносуспензии с частицами алмаза хорошо описывается теорией Максвелла (см. таблицу).

Типичное поведение массы образца в процессе испарения из тигля объемом $20 \mu 1$ для наножидкости с частицами оксида алюминия в зависимости от времени эксперимента показано на рис. 4, $a$. В данном случае объем тигля с жидкостью сопоставим с размерами капель, испарение которых изучалось ранее. На рис. 4 , а видна зависимость скорости потери массы наножидкости от концентрации наночастиц: чем выше концентрация наночастиц, тем быстрее идет потеря массы жидкости. Кроме того, необходимо отметить один важный момент, о котором ничего не говорилось в предыдущих исследованиях. Объем наножидкости складывается из объема самой жидкости и объема наночастиц. Таким образом, наножидкость содержит в себе меньшее количество жидкости, которое может испариться, по сравнению с чистой жидкостью. Этот эффект очень хорошо виден на рис. 4, $а$. После испарения всей жидкости на весах остается масса, равная массе наночастиц, соответствующей их первоначальной концентрации в растворе. При высоких концентрациях наночастиц этот эффект может весьма существенно повлиять на интерпретацию результатов исследований. Так, например, для объемной концентрации наночастиц 4 vol.\% оставшаяся масса наночастиц составляет около $16 \mathrm{wt} . \%$, что сопоставимо с величиной самого эффекта от добавки наночастиц на скорость испарения. Поэтому для исключения этого момента в настоящей работе анализировалась скорость потери чистой массы жидкости в процессе испарения без учета массы наночастиц. Подобный анализ, видимо, был сделан впервые. Пример таких данных показан на рис. $4, b$, на котором приведена зависимость от времени оставшейся массы воды в процентах от первоначальной массы. Как видно, в таком представлении с увеличением 

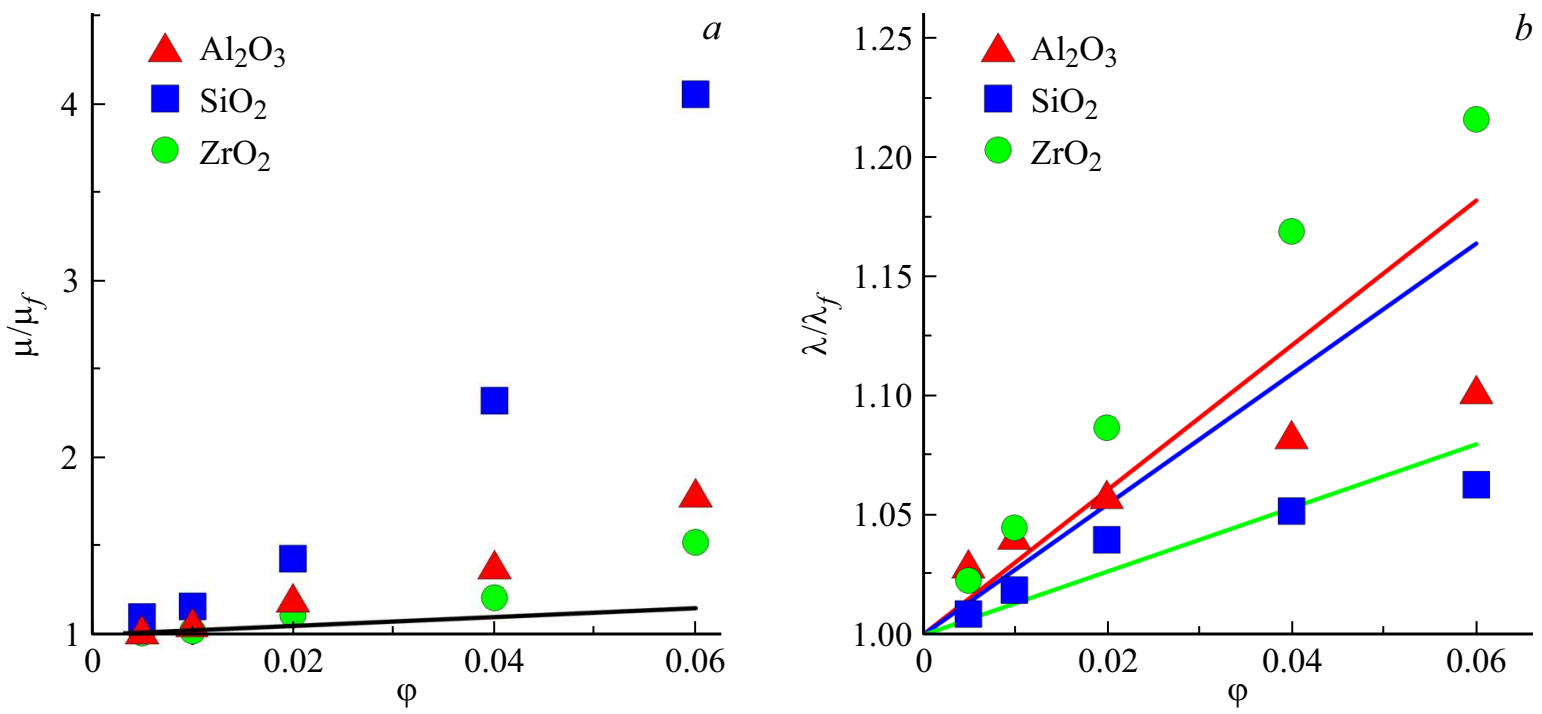

Рис. 3. Зависимость коэффициентов вязкости $(a)$ и теплопроводности $(b)$ наножидкости от концентрации наночастиц $\mathrm{SiO}_{2}(25 \mathrm{~nm})$, $\mathrm{ZrO}_{2}(105 \mathrm{~nm})$, и $\mathrm{Al}_{2} \mathrm{O}_{3}(43 \mathrm{~nm})$.
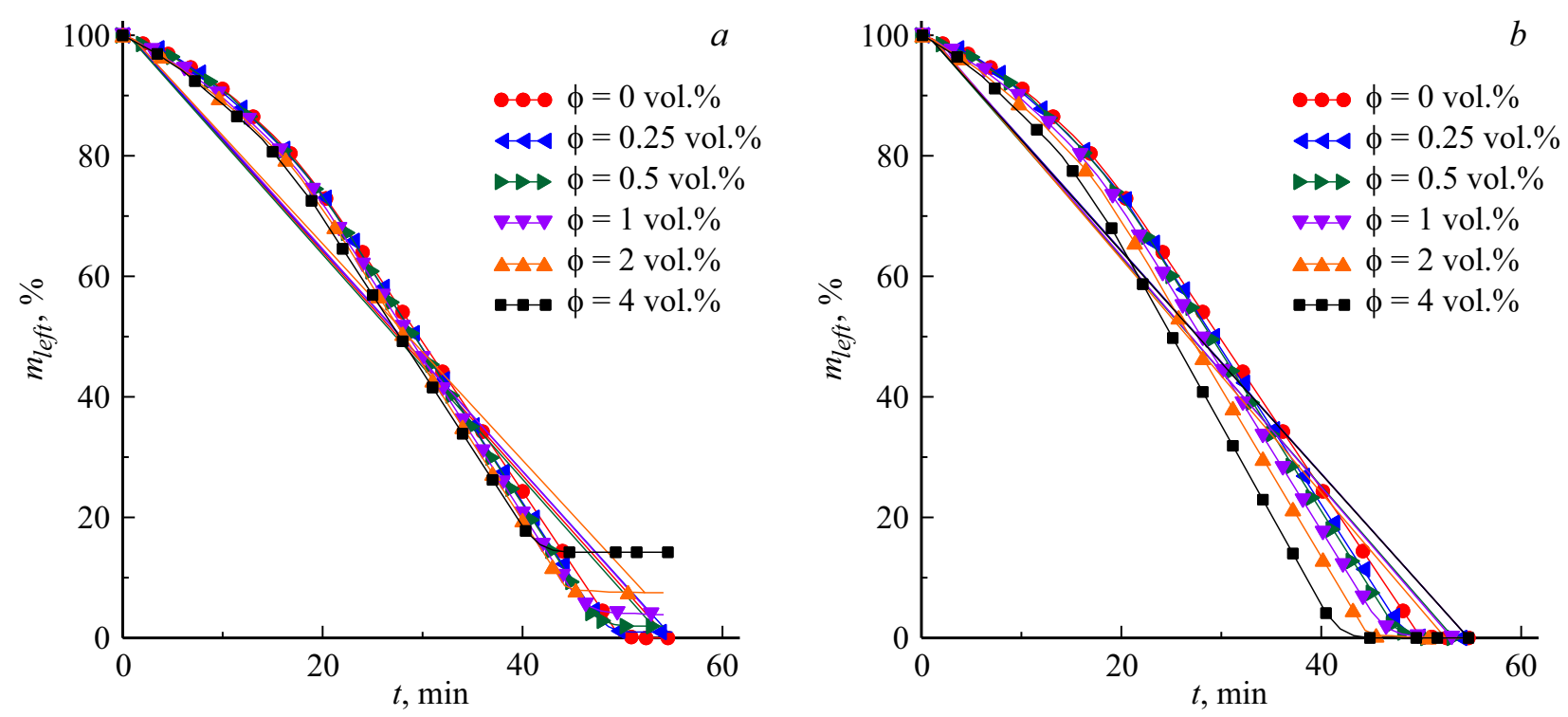

Рис. 4. Зависимость от времени оставшейся массы наножидкости $(a)$ и оставшейся массы базовой жидкости $(b)$ для разных концентраций наночастиц оксида алюминия.

концентрации наночастиц скорость испарения монотонно увеличивается.

На рис. 5 приведены результаты исследования процесса испарения наножидкости с частицами оксида кремния. Здесь показана зависимость от времени относительного увеличения массы испарившейся жидкости, которая определялась следующим образом:

$$
\eta=\frac{m_{n f}-m_{w}}{m_{n f}} \cdot 100 \%
$$

где $m_{n f}$ - масса испарившейся наножидкости, $m_{w}-$ масса испарившейся в тех же условиях воды. Как видно из приведенных данных, с увеличением концентрации наночастиц количество испарившейся жидкости монотонно возрастает. При этом даже при очень высокой объемной концентрации частиц (6 vol.\%) это увеличение составляет всего около $12 \%$.

На основе полученных данных о динамике потери массы в процессе эксперимента была вычислена скорость испарения наножидкости $w_{\text {evap }}=\partial m / \partial t$. Здесь производная по времени вычислена с помощью центральноразностной схемы без применения какого-либо сглаживания. Зависимость скорости испарения наножидкости с частицами оксида кремния от времени эксперимента 


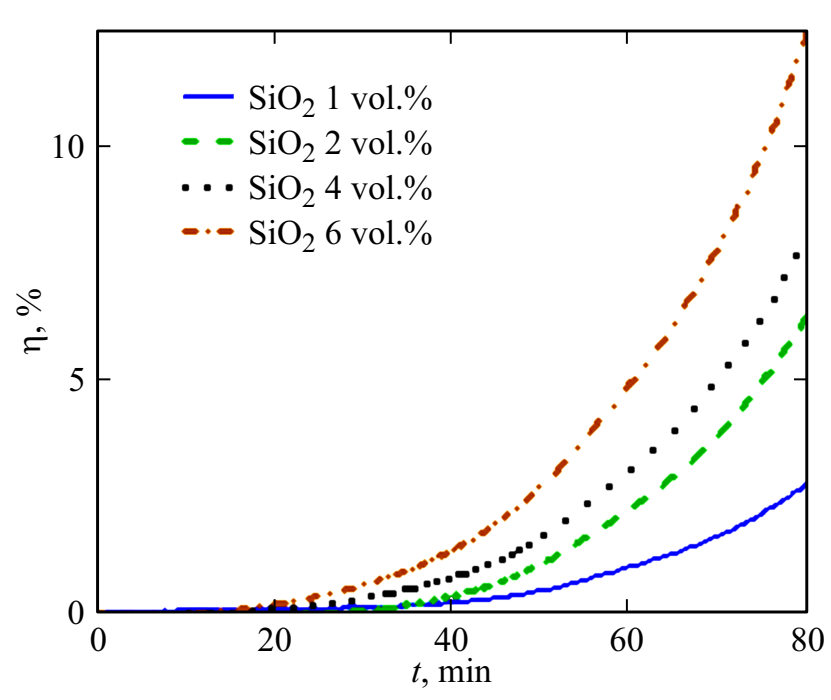

Рис. 5. Зависимость относительного увеличения массы испарившейся наножидкости по сравнению с массой испарившейся воды для различных объемных концентраций наночастиц $\mathrm{SiO}_{2}$.

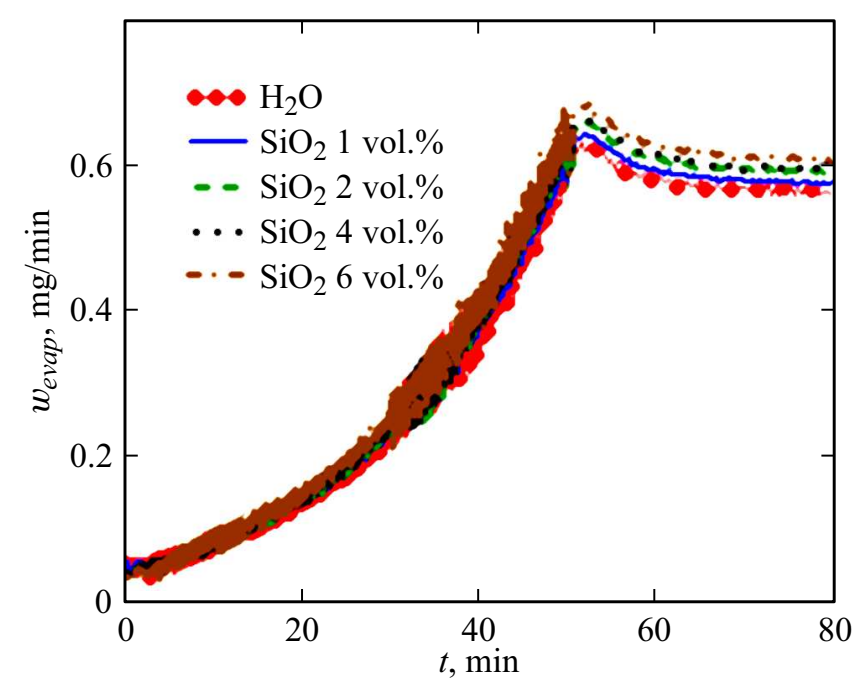

Рис. 6. Зависимость от времени удельной скорости испарения жидкостей в процессе всего эксперимента для различных объемных концентраций наночастиц $\mathrm{SiO}_{2}$.

показана на рис. 6. Эта зависимость имеет два различных участка: первый связан с нагревом образцов на нем скорость испарения возрастает за счет увеличения температуры жидкости; далее наблюдается некоторый переходной процесс, связанный со стабилизацией температуры после выключения нагрева, на котором скорость испарения немного снижается, и далее на этапе изотермической выдержки скорость испарения выходит на установившееся значение. Из этого рисунка видно, что с увеличением объемной концентрации наночастиц скорость испарения наножидкости заметно повышается.
Аналогичные измерения были проведены и для других наножидкостей, при этом были получены качественно аналогичные описанным выше результаты. Результаты измерений в виде зависимости относительной скорости испарения от концентрации частиц $w(\varphi)$ показаны на рис. 7. Здесь под относительной скоростью испарения следует понимать скорость испарения наножидкости, отнесенную к скорости испарения чистой воды в тех же условиях. Качественно зависимости скорости испарения от концентрации частиц для различных материалов похожи, однако количественно они несколько отличаются. С увеличением концентрации наночастиц скорость испарения жидкости увеличивает. При больших концентрациях наночастиц скорость испарения выходит на плато. Видно, что наножидкости с оксидными частицами имеют близкую между собой скорость испарения. Для этих наножидкостей если и есть зависимость от материала наночастиц, то она, по-видимому, слабая.

Анализ результатов экспериментов показывает, что зависимость скорости испарения наножидкости с хорошей точностью описывается корреляцией вида $w(\varphi)=1+a \varphi^{b}$. Коэффициенты $a$ и $b$ были определены для всех исследуемых наножидкостей (рис. 7):

$$
\begin{aligned}
& w(\varphi)=1+0.115 \varphi^{0.428} \text { для частиц алмаза; } \\
& w(\varphi)=1+0.033 \varphi^{0.551} \text { для частиц диоксида кремния; } \\
& w(\varphi)=1+0.034 \varphi^{0.419} \text { для частиц оксида алюминия; } \\
& w(\varphi)=1+0.053 \varphi^{0.294} \text { для частиц диоксида циркония. }
\end{aligned}
$$

Наножидкость с частицами алмаза испаряется существенно быстрее остальных, но даже в этом случае

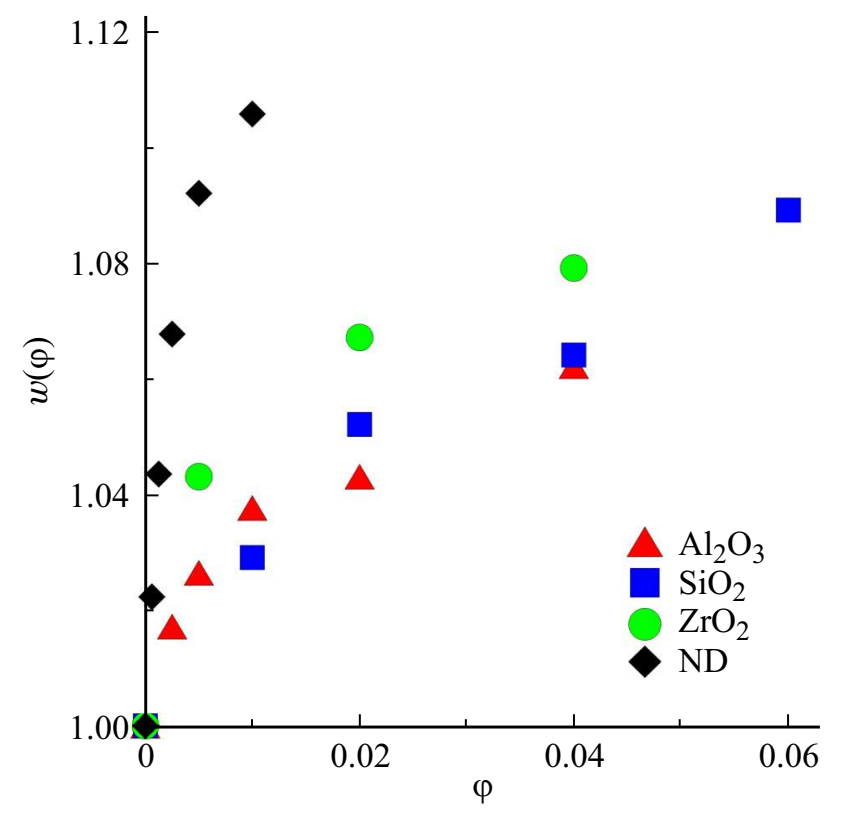

Рис. 7. Зависимость относительной скорости испарения наножидкостей от концентрации частиц. 
приращение скорости испарения составляет около $12 \%$ при достаточно высокой концентрации наночастиц, равной 1 vol.\%.

Для наножидкостей с оксидными частицами была предпринята попытка связать скорость испарения с их теплофизическими свойствами (вязкостью и теплопроводностью). Как видно, вязкости, теплопроводности и скорости испарения всех рассмотренных наножидкостей с увеличением концентрации наночастиц возрастают. При этом на качественном уровне прослеживается следующая взаимосвязь: при одинаковой концентрации наночастиц скорость испарения наножидкости тем выше, чем выше ее коэффициент теплопроводности и меньше вязкость. Так, например, наножидкость с частицами диоксида циркония при одинаковой концентрации частиц имеет минимальную вязкость и максимальный коэффициент теплопроводности и при этом обладает максимальной скоростью испарения. Наножидкость с частицами диоксида кремния, напротив, имеет максимальную вязкость и минимальный коэффициент теплопроводности и при этом имеет самую низкую скорость испарения. Однако на количественном уровне установить связь скорости испарения со свойствами жидкости не удается. Это связано с разной чувствительностью различных свойств наножидкости к концентрации наночастиц. Так, например, вязкость наножидкости с частицами диоксида кремния примерно в четыре раза выше, чем вязкость наножидкости с частицами диоксида циркония, при этом скорость их испарения отличается меньше, чем на 3\%. Таким образом, этот вопрос требует дальнейшего изучения.

\section{Заключение}

В работе было проведено экспериментальное исследование испарения наножидкостей на основе воды и наночастиц диоксидов кремния и циркония, оксида алюминия, а также наноалмазов при различных объемных концентрациях частиц.

Анализ имеющихся публикаций по испарению наножидкости показал, что результаты экспериментов противоречивы и разрознены. Во многом это обусловлено тем, что исследование скорости испарения само по себе является достаточно сложной задачей. При проведении экспериментов необходимо не только с хорошей точностью измерять массу образца, но тщательно контролировать температуру и давление во внешней среде. Для решения этой задачи в работе был использован высокоточный прибор синхронного термоанализа STA 449 C Jupiter (фирма NETZSCH).

В отличие от большинства ранее выполненных работ по данной тематике, в настоящей работе впервые исследовалось влияние наночастиц на скорость испарения чистой жидкости без учета массы наночастиц.

Получены зависимости скорости испарения от объемной концентрации наночастиц. В результате эксперимен- тов было показано, что с увеличением концентрации наночастиц скорость испарения жидкости монотонно возрастает. При этом приращение скорости испарения жидкости не очень значительно. Максимальное приращение скорости испарения от добавки наночастиц по сравнению с базовой жидкости для оксидных наночастиц составляет около 10\% при достаточно высокой концентрации в 6 vol.\%. Установлено, что существенно большее влияние на скорость испарения по сравнению с оксидными частицами имеют наночастицы алмаза, которые позволяют повысить скорость испарения примерно на $12 \%$ уже при объемной концентрации 1 vol.\%. Однако при этом необходимо отметить, что наночастицы алмаза являлись самыми мелкими в данном исследовании, их размер был около $5 \mathrm{~nm}$. Подобно остальным свойствам наножидкости, таким как вязкость и теплопроводность, здесь очевидно также ожидать зависимости скорости испарения от размера наночастиц. Исследовать зависимость испарения наножидкости от размера наночастиц планируется в дальнейшем.

\section{Финансирование работы}

Работа выполнена при частичном финансировании Российского фонда фундаментальных исследований, правительства Красноярского края, Красноярского краевого фонда поддержки научной и научно-технической деятельности в рамках научного проекта № 18-48243019. Исследования испарения суспензии наноалмазов выполнено в рамках государственного задания СФУ (№ 16.8368.2017).

\section{Конфликт интересов}

Авторы заявляют, что у них нет конфликта интересов.

\section{Список литературы}

[1] Choi S.U.S. // ASME FED. 1995. Vol. 66. P. 3408-3416.

[2] Kumar Das S., Choi S.U.S., Wenhua Y., Pradeep T. Nanofluids: science and technology. John Wiley \& Sons, 2008. $416 \mathrm{p}$.

[3] Pryazhnikov M.I., Minakov A.V., Rudyak V.Ya., Guzei D.V. // Int. J. Heat. Mass. Tran. 2017. Vol. 104. N 1. P. 1275-1282.

[4] Терехов В.И., Калинина С.В., Леманов В.В. // Теплофизика и аэромеханика. 2010. № 2. С. 173-188.

[5] Minakov A.V., Guzei D.V., Pryazhnikov M.I., Zhigarev V.A., Rudyak V.Y. // Int. J. Heat. Mass. Tran. 2016. Vol. 102. P. 745 755.

[6] Гузей Д.В., Минаков А.В., Рудяк В.Я., Дектерев А.А. // Письма в ЖТФ. 2014. Т. 40. Вып. 5. С. 34-42. [Guzei D.V., Minakov A.V., Rudyak V.Ya., Dekterev A.A. // Tech. Phys. Lett. 2014. Vol. 40. N 3. P. 203-206.]

[7] Sefiane K., Bennacer R. // Adv. Colloid Interfac. 2009. Vol. 147-148. P. 263-271.

[8] Gan Y., Qiao L. // Int. J. Heat. Mass. Tran. 2012. Vol. 55. P. 5777-5782. 
[9] Nazarov A.D., Miskiv N.B., Bochkareva E.M. // J. Phys. Conf. Ser. 2018. Vol. 1105. 012095. doi: 10.1088/17426596/1105/1/012095.

[10] Borisov A., Nazarov A., Serov A., Mamonov V. // MATEC Web Conf. 2017. Vol. 115. 08009. DOI: $10.1051 / \mathrm{matec}$ conf/20171150800 STS-33.

[11] Терехов В.И., Шишкин Н.Е. // Сборник научных статей современная наука. 2011. Т. 7. Вып. 2. С. 197-200.

[12] Терехов В.И., Шишкин Н.Е. // Письма в ЖТФ. 2012. Т. 34. Вып. 1. С. 51-57.

[13] Tanvir S., Jain S., Qiao L. // J. Appl. Phys. 2015. Vol. 118. № 014902 .

[14] Ameen M.M., Prabhul K., Sivakumar G., Abraham P.P., Jayadeep U.B. Sobhan C.B. // Int. J. Thermophys. 2010. Vol. 31. N 6. P. 1131-1144.

[15] Lee S., Phelan P.E., Dai L., Prasher R., Gunawan A., Taylor R.A. // Appl. Phys. Lett. 2014. Vol. 104. N 15. 151908.

[16] Gan Y., Qiao L. // Energy Fuels. 2012. Vol. 26. P. 4224-4230.

[17] Высокоморная О.В., Пискунов М.В., Щербинина А.А. // Ползуновский вестник. 2016. № 1. С. 96-101.

[18] Tso C.Y., Chao C.Y.H. // Int. J. Heat. Mass. Tran. 2015. Vol. 84. P. 931-941.

[19] Gnanadason M.K., Kumar P.S., Rajakumar S., Yousuf M.H.S. // I.J.AERS. 2011. Vol. 1. P. 171-177.

[20] Kabeel A.E., Omara Z.M., Essa F.A. // Energ. Convers. Manage. 2014. Vol. 86. P. 268-274.

[21] Omara Z.M., Kabeel A.E., Essa F.A. // Energ. Convers. Manage. 2015. Vol. 103. P. 965-972.

[22] Рудяк В.Я., Минаков А.В., Сметанина М.С., Пряжников М.И. // Докл. РАН. 2016. Т. 467. № 3. С. 289-292.

[23] Рудяк В.Я., Минаков А.В., Пряжников М.И. // Письма в ЖТФ. 2016. Т. 42. Вып. 2. С. 9-16.

[24] Minakov A.V., Rudyak V.Ya., Pryazhnikov M.I. // Colloid Surface A. 2018. Vol. 554. P. 279-285.

[25] Минаков А.В., Рудяк В.Я., Гузей Д.В., Пряжников М.И., Лобасов А.С. // Инженерно-физический журнал. 2015. T. 88. № 1. C. $148-160$.

[26] Пряжников М.И., Гузей Д.В., Минаков А.В., Лобасов А.С. // Журнал Сибирского федерального ун-та. Серия: Техника и технологии. 2015. Т. 8. Вып. 2. С. 153-165.

[27] Pryazhnikov M.I., Minakov A.V., Rudyak V.Ya., Guzei D.V. // Int. J. Heat. Mass. Tran. 2017. Vol. 104. N 1. P. 1275-1282. 